\title{
LOS NIÑOS Y NIÑAS EN TIEMPOS DE FACEBOOK: ESPECIAL REFERENCIA A LOS HUÉRFANOS DIGITALES
}

\author{
CHILDREN IN THE FACEBOOK ERA: SPECIAL REFERENCE \\ TO DIGITAL ORPHANS
}

Bruno Novoa Campos ${ }^{1}$

\section{Resumen:}

El autor desarrolla el marco jurídico referencial y desarrollo jurisprudencial relevante del derecho de los niños y de las niñas; posteriormente, pone en vitrina un problema del presente siglo: los huérfanos digitales.

Palabras clave: Derecho de los niños.

\begin{abstract}
:
The author explains the reference legal framework and relevant caselaw on children's rights. Then, he presents a problem of this century: the digital orphans.
\end{abstract}

Keywords: Children's Rights.

Docente de la Universidad Femenina del Sagrado Corazón - UNIFÉ y del Centro de Estudios Constitucionales del Tribunal Constitucional. Miembro de la Asociación Peruana de Derecho Constitucional. Correo electrónico: derechoconstitucionalperu@gmail.com 


\section{MARCO JURÍDICO REFERENCIAL}

Iniciaremos citando el marco jurídico referencial del presente tema. Para ello, consideramos pertinente mencionar el Código del Niño y Adolescente, aprobado por Ley № 27337, que establece el interés superior de nuestros niños, como se observa a continuación:

"Artículo IX.- Interés superior del niño y del adolescente.- En toda medida concerniente al niño y al adolescente que adopte el Estado a través de los Poderes Ejecutivo, Legislativo y Judicial, del Ministerio Público, los Gobiernos Regionales, Gobiernos Locales y sus demás instituciones, así como en la acción de la sociedad, se considerará el Principio del Interés Superior del Niño y del Adolescente y el respeto a sus derechos."

Por su parte, la Constitución Política del Perú (en adelante, la CPP) señala que la comunidad y el Estado protege al niño y a la niña, tal como se aprecia a continuación:

"Artículo 4".- La comunidad y el Estado protegen especialmente al niño, al adolescente (...)"

Asimismo, la Convención sobre los Derechos del Niño de 1989, aprobada por la Asamblea General de las Naciones Unidas el 20 de noviembre de 1989 y ratificada por el Estado Peruano mediante Resolución Legislativa № 25278 del 3 de agosto de 1990, protege al niño y niña y, establece deberes a los padres, tutores y Estado, tal como se observa a continuación:

\section{“Artículo 3}

1. En todas las medidas concernientes a los niños que tomen las instituciones públicas o privadas de bienestar social, los tribunales, las autoridades administrativas o los órganos legislativos, una consideración primordial a que se atenderá será el interés superior del niño.

2. Los Estados Partes se comprometen a asegurar al niño la protección yel cuidado que sean necesarios para su bienestar, teniendo en cuenta los derechos y deberes de sus padres, tutores $u$ otras personas responsables de él ante la ley $y$, con ese fin, tomarán todas las medidas legislativas y administrativas adecuadas.

3. Los Estados Partes se asegurarán de que las instituciones, servicios y establecimientos encargados del cuidado o la protección de los niños cumplan 
las normas establecidas por las autoridades competentes, especialmente en materia de seguridad, sanidad, número y competencia de su personal, así como en relación con la existencia de una supervisión adecuada."

\section{"Artículo 27}

1. Los Estados Partes reconocen el derecho de todo niño a un nivel de vida adecuado para su desarrollo físico, mental, espiritual, moral y social.

2. A los padresu otras personas encargadas del niñoles incumbela responsabilidad primordial de proporcionar, dentro de sus posibilidades y medios económicos, las condiciones de vida que sean necesarias para el desarrollo del niño.

3. Los Estados Partes, de acuerdo con las condiciones nacionales y con arreglo a sus medios, adoptarán medidas apropiadas para ayudar a los padres y a otras personas responsables por el niño a dar efectividad a este derecho $y$, en caso necesario, proporcionarán asistencia material y programas de apoyo, particularmente con respecto a la nutrición, el vestuario y la vivienda.

4. Los Estados Partes tomarán todas las medidas apropiadas para asegurar el pago de la pensión alimenticia por parte de los padres u otras personas que tengan la responsabilidad financiera por el niño, tanto si viven en el Estado Parte como si viven en el extranjero. En particular, cuando la persona que tenga la responsabilidad financiera por el niño resida en un Estado diferente de aquel en que resida el niño, los Estados Partes promoverán la adhesión a los convenios internacionales o la concertación de dichos convenios, así como la concertación de cualesquiera otros arreglos apropiados."

\section{JURISPRUDENCIA CONSTITUCIONAL RELEVANTE}

Por otro lado, el Tribunal Constitucional (en adelante, el TC) establece el principio constitucional de protección del interés superior del niño y niña como contenido implícito del artículo $4^{\circ}$ de la CPP citado anteriormente, como se puede apreciar:

"El principio constitucional de protección del interés superior del niño, niña y adolescente constituye un contenido constitucional implicito del artículo $4^{\circ}$ de la Norma Fundamental en cuanto establece que "La comunidad y el Estado protegen especialmente al niño, al adolescente, (...)" (EXP. N. ${ }^{\circ}$ 02132-2008-PA/TC)

Del mismo modo, el TC hace énfasis en el cumplimiento del referido principio por parte del Estado, de la sociedad y también, de los padres y/o tutores responsables, como se aprecia a continuación: 
"De este modo, el principio constitucional de protección del interés superior del niño, niña y adolescente se constituye en aquel valor especial y superior según el cual los derechos fundamentales del niño, niña y adolescente, y en última instancia su dignidad, tienen fuerza normativa superior no sólo en el momento de la producción de normas, sino también en el momento de la interpretación de ellas, constituyéndose por tanto en un principio de ineludible materialización para el Estado, la sociedad en su conjunto y la propia familia, incluidos claro está el padre, la madre o quien sea el responsable de velar por su derechos fundamentales. (EXP. N. ${ }^{\circ}$ 02132-2008-PA/TC)

Adicionalmente, el TC precisa que los intereses del Estado, de la sociedad, de los padres o tutores, no podrán anteponerse a los derechos fundamentales del niño y de la niña, como se observa a continuación:

"El hecho de que un niño o una niña tengan un padre, madre o responsable de su tutela, no implica en modo alguno que la protección de su dignidad o su desarrollo físico, psíquico o social se vean supeditados a la voluntad de tales personas adultas. Ni el interés del padre, madre o responsable de su tutela, ni aquellos intereses del Estado o de la sociedad pueden anteponerse a aquellos derechos fundamentales de los niños, niñas y adolescentes" (EXP. N. ${ }^{\circ}$ 02132-2008-PA/TC)

\section{ESPECIAL REFERENCIA A LOS HUÉRFANOS DIGITALES}

Como hemos apreciado, los derechos del niño y de la niña se encuentran consagrados a nivel legal, constitucional e internacional. Del mismo modo, el TC ha desarrollado el principio constitucional de protección del interés superior del niño y de la niña para el adecuado resguardo de sus derechos.

Sin embargo, no estamos seguros si los derechos consagrados y la jurisprudencia emitida alcanzan a defender los derechos del niño y de la niña en tiempos donde las redes sociales "conviven con las familias".

Para la Organización de los Estados Americanos - OEA, las redes sociales tienen el significado siguiente:

"son formas de interacción social, definida como un intercambio dinámico entre personas, grupos e instituciones. Un sistema abierto y en construcción permanente que involucra a conjuntos que se identifican en las mismas necesidades y problemáticas y que se organizan para potenciar sus recursos. La intervención en red es un intento reflexivo y organizador de esas interacciones e intercambios, donde el sujeto se funda a sí mismo diferenciándose de otros." (OEA, 2009) 
Por lo que de acuerdo a la definición, a través de las redes sociales en Internet tenemos la posibilidad de interactuar con públicos diversos aunque no los conozcamos, el sistema es abierto y se va afianzando con lo que cada usuario aporta. (OEA, 2009)

Interacción abierta que pondría en desventaja a los niños y niñas que se encuentren como sus principales usuarios. Más aún, si como bien indica la OEA, podrían interactuar con personas que desconocen.

Los niños y niñas se conectan a Internet en distintos lugares, dependiendo del contexto y las políticas de cada país. Por ejemplo, en Colombia la escuela constituye el principal punto de acceso, mientras que en Costa Rica (56\%), el Ecuador (64\%), El Salvador (81\%), México (60\%) y el Perú (67\%) es el hogar. (UNICEF, 2014)

Ahora bien, el panorama descrito se complica si los niños y niñas utilizan internet en casa, o incluso fuera de ella, sin la supervisión de sus padres o de tutores siendo lamentablemente, por defecto, ellos mismos quienes toman las riendas de sus propias crianzas orientados $u$ orientadas por un mundo tecnológico paralelo al que ingresan sin límites y con gran facilidad.

Si bien faltan datos respecto de cómo actúan los padres y madres frente al uso de Internet en los hogares, es posible estimar que los conocimientos mediáticos y tecnológicos de niños y niñas superan a los de sus progenitores, por lo que estos no están a la par para orientarlo. (UNICEF, 2014)

Aunado a lo antes referido, se suma un factor adicional complejo, poco conocido y por ende peligroso, así como muy propio del presente siglo: padres que omiten la crianza de sus hijos por encontrarse "conectados en las redes sociales".

La doctrina viene denominando a este fenómeno como "huérfanos digitales", concepto que considera a los niños, niñas y jóvenes, también llamados nativos digitales, que si bien poseen herramientas tecnológicas, están informatizados, y se atreven a explorar sin miedo Internet, no cuentan con los criterios de selección y evaluación de la información, pues, aunque las familias indican que establecen reglas para la navegación, no están presentes durante la mayor parte del tiempo para cautelar que esas reglas se cumplan, de esta manera, de nativos no alcanzan a convertirse en usuarios informacionales, por ello se transforman en huérfanos digitales (Ponce de León, 2016) 
Este fenómeno, resulta significativo si observamos las últimas cifras brindadas por el Instituto Nacional de Estadística e Informática - INEI que muestra el altísimo uso del internet por nuestros niños y niñas así como, su aumento considerable, como observamos a continuación:

Según los resultados preliminares obtenidos, en el trimestre eneromarzo 2017, el 89,6\% de niñas, niños y adolescentes hacen uso del internet para actividades de entretenimiento como juegos de videos y obtener películas o música, entre otras, el $74,2 \%$ para comunicarse (email, chat, etc.) y el $72,5 \%$ para obtener información. Comparando con igual trimestre del año anterior, las actividades de entretenimiento aumentó significativamente en 6,4 puntos porcentuales (INEI, 2017).

Gráficamente, acorde al INEI, se aprecia del modo siguiente:

\section{CUADRO № 05}

Perú: Población de 6 a 17 años de edad que hace uso de internet, según tipo de actividad que realiza.

Trimestre: Enero-Febrero-Marzo 2016 y 2017.

(Porcentaje sobre el total de usuarios de internet de 6 a 17 años de edad).

\begin{tabular}{|c|c|c|c|}
\hline \multirow{2}{*}{$\begin{array}{c}\text { Tipo de actividad } \\
\text { que realiza }\end{array}$} & \multicolumn{2}{|c|}{ Trimestre } & $\begin{array}{c}\text { Variación } \\
\text { absoluta (Puntos } \\
\text { porcentuales) }\end{array}$ \\
\cline { 2 - 3 } & $\begin{array}{c}\text { Ene-Feb-Mar } \\
\mathbf{2 0 1 6}\end{array}$ & $\begin{array}{c}\text { Ene-Feb-Mar 2017 } \\
\mathbf{P I}\end{array}$ & $-0,3$ \\
\hline Obtener información & 72,8 & 72,5 & $-2,4$ \\
\hline $\begin{array}{c}\text { Comunicarse (email, } \\
\text { chat, etc.) }\end{array}$ & 76,6 & 74,2 & $-0,6$ \\
\hline $\begin{array}{c}\text { Educación } \\
\text { formal/Capacitación }\end{array}$ & $(3,9)$ & $(3,3)$ & $6,4^{* * *}$ \\
\hline $\begin{array}{c}\text { Actividades de } \\
\text { entretenimiento }\end{array}$ & 83,2 & 89,6 & $-1,3$ \\
\hline \begin{tabular}{c} 
Otras actividades 1/ \\
\hline
\end{tabular} & $(3,9)$ & $(2,6)$ & \\
\hline
\end{tabular}

Fuente: Instituto Nacional de Estadística e Informática - Encuesta Nacional de Hogares.

1/ Comprende comprar productos y/o servicios, operaciones de banca electrónica/servicios financieros, transacciones con organizaciones estatales/autoridades públicas.

( ) Comprende a estimadores con coeficiente de variación mayor a 15\% considerados como referenciales. P/ Preliminar.

* Diferencia significativa $(\mathrm{p}<0.10)$.

** Diferencia altamente significativa $(\mathrm{p}<0.05)$.

*** Diferencia muy altamente significativa $(\mathrm{p}<0.01)$. 
Por último, compartimos algunas frases de menores que expresan su interrelación casi familiar, buena y/o mala, con las redes sociales:

- $\quad$ "Facebook representa un lugar en el que me puedo comunicar con mis amigos, subir fotos mías o con ellos. Es mi perfil virtual". Rocío, 14 años.

- "Si dejara de existir Facebook no sería el fin del mundo, pero seguramente saldría una nueva red social parecida". Paz, 17 años.

- "Si no hubiera, se acabaría el cyberbullying, los acosos y todo eso". Santiago, 13 años.

- $\quad$ "Lo bueno es que me comunico, lo malo es tener un malentendido porque por mensaje escrito uno no percibe cómo te dice las cosas el otro". Salvador, 14 años.

- $\quad$ "Lo malo es que hay gente que te agrega sin saber quién eres, para tratarte mal o para acosarte". Rocío, 12 años.

- "Facebook es como parte de mi vida, entrar es algo normal, cotidiano". Victoria, 15 años.

- "Yo lo uso para poner algunas fotos con mis amigos, lo malo es que todas mis publicaciones están expuestas a personas desconocidas". Facundo, 17 años.

- “Creo que Facebook nos une y nos comunicamos más fácilmente, pero querer ocultar cierta información es difícil". Simón, 16 años. (UNICEF, 2014)

\section{A MANERA DE CONCLUSIÓN}

Finalmente, hemos considerado importante abordar un tema que no se encuentra en agenda nacional en nuestro medio, menos a nivel oficial y con poca importancia a nivel académico, pero que debe llamar a la reflexión, más aún si cada día que dejemos de tenerlo presente el internet, que no suele pedir permiso, hace el papel de Estado, sociedad, padres y/o tutores.

En tal escenario, compartimos, a manera de conclusión, los e-derechos de los niños y las niñas que UNICEF presentó en forma de decálogo y que esperamos sean compartidos, promocionados, aplicados $\mathrm{y}$, acorde a nuestro 
contexto mejorados, por todas las entidades públicas, organizaciones sociales, padres de familia, tutores y todos los lectores que, al igual que el autor del artículo, se haya sentido avergonzado o avergonzada por su omisión diaria al observar acciones clarísimas en la intimidad familiar y por permitir que "facebook" -o como se llame en el 2050- sea quien brinde las lecciones a nuestros y nuestras hijos, hijas, sobrinos, sobrinas, nietos, nietas o cualquier menor que al momento en que culmine de leer este escrito quiera estar con él o ella.

\section{Decálogo de los e-derechos de los niños y niñas}

1. Derecho al acceso a la información sin discriminación por sexo, edad, recursos económicos, nacionalidad, etnia o lugar de residencia. Este derecho se aplicará en especial a los niños y niñas discapacitados.

2. Derecho a la libre expresión y asociación. A buscar, recibir y difundir informaciones e ideas de todo tipo por medio de la red. Estos derechos solo se restringirán para garantizar la protección de los niños y niñas frente a informaciones perjudiciales para su bienestar, desarrollo e integridad; y para garantizar el cumplimiento de las leyes, la seguridad, los derechos y la reputación de otras personas.

3. Derecho de los niños y niñas a ser consultados y a dar su opinión cuando se apliquen leyes o normas a Internet que les afecten.

4. Derecho a la protección contra la explotación, el comercio ilegal, los abusos y la violencia de todo tipo.

5. Derecho al desarrollo personal y a la educación, y a todas las oportunidades que las nuevas tecnologías puedan aportar para mejorar su formación.

6. Derecho a la intimidad de las comunicaciones por medios electrónicos. Derecho a no proporcionar datos personales por Internet, a preservar su identidad y su imagen de posibles usos ilícitos.

7. Derecho al esparcimiento, al ocio, a la diversión y al juego, mediante Internet y otras tecnologías. Derecho a que los juegos y las propuestas de ocio no contengan violencia gratuita, ni mensajes racistas, sexistas o denigrantes y que respeten los derechos y la imagen de los niños y niñas y otras personas. 
8. Los padres y madres tendrán el derecho y la responsabilidad de orientar y acordar con sus hijos e hijas un uso responsable.

9. Los gobiernos de los países desarrollados deben comprometerse a cooperar con otros países para facilitar el acceso de estos y sus ciudadanos, y en especial de los niños y niñas, a Internet y otras tecnologías para promover su desarrollo y evitar la creación de una nueva barrera entre los países ricos y los países pobres.

10. Derecho a beneficiarse y a utilizar en su favor las nuevas tecnologías para avanzar hacia un mundo más saludable, pacífico, solidario, justo y respetuoso con el medioambiente, en el que se respeten los derechos de todos los niños y niñas. (UNICEF, 2014)

\section{REFERENCIAS}

Fondo de las Naciones Unidas para la Infancia - UNICEF (setiembre 2014). Derechos de la infancia en la era digital. Desafíos, boletín de la infancia y adolescencia sobre el avance de los Objetivos de Desarrollo del Milenio, Número 18, ISSN 1816-7535.

Organización de los Estados Americanos - OEA (2009). Guía de manejo de redes sociales de internet. Recuperado de: http://portal.oas.org/LinkClick. aspx?fileticket $=$ RHIdC3cS3Qw\%3D\&tabid $=1483$

Ponce de León Leiva, Rossana (abril 2016). Participación de la familia en la sociedad virtual: conocimiento sobre los usos y riesgos de internet. Suplemento "SIGNOS EAD" pp. 2 -13.

Instituto Nacional de Estadística e Informática - INEI (junio 2017). Estado de la niñez y adolescencia. Informe Técnico $N^{\circ} 2$. Recuperado de : http://m.inei. gob.pe/media/MenuRecursivo/boletines/03-informe-tecnico-n03_ninez-yadolescencia-abr-may-jun2017.

Fecha de recepción: 31 de agosto de 2017

Fecha de aceptación: 17 de setiembre de 2017 